\title{
Pengaruh Bentuk Formulasi dan Waktu Aplikasi Kulit Buah Jengkol pada Pertumbuhan Padi Sawah Asal Bibit
}

\author{
The Effect Of Formulation And The Application Of Jengkol Pod Exocarp \\ On Paddyrice Seedling Growth
}

\author{
Uswatun Nurjanah $^{1^{*}}$, Prapto Yudono ${ }^{2}$, A.T. Suyono ${ }^{2}$, dan Dja'far Shieddiq ${ }^{3}$ \\ 1. Program Studi Agroekoteknologi, Fakultas Pertanian Universitas Bengkulu \\ 2. Jurusan Budidaya Pertanian, Fakultas Pertanian Universitas Gajah Mada \\ 3. Jurusan Ilmu Tanah, Fakultas Pertanian Universitas Gajah Mada \\ *. Uswatun_unib@yahoo.co.id
}

\begin{abstract}
ABSRTACT
Jengkol pod exocarp can be used as anorganic fertilizer for rice cultivation. A research aimed to determine an appropriate formulation and application time of jengkol pod exocarp on paddy rice seedling growth. This study consisted of 2 factors. The first factor was formulation, namely liquid, powder or granules. The second factor was time of application, namely at planting, 1 or 2 weeks after planting. These treatments were arranged in a Completely Randomized Design with 3 replications. The results showed that the application of jengkol pod exocarp in the form of granule improved root growth, $N, P, K$ uptake, photosynthesis rate, but not dry weight. The time application of jengkol pod exocarp two weeks after planting increased $N$ and $P$ uptake, transpiration rate, photosynthesis rate and root dry weight.
\end{abstract}

Key words: jengkol pod exocarp, formulation, application time, paddy rice seedling, nutrient uptake

\begin{abstract}
ABSTRAK
Kulit buah jengkol dapat digunakan sebagai pupuk organik pada pertanaman padi sawah. Penelitian ini betujuan untuk menjelaskan bentuk formulasi dan waktu aplikasi kulit buah jengkol pada pertumbuhan padi sawah asal bibit. Penelitian ini menggunakan Rancangan Acak Lengkap (RAL) faktorial 3×3+3 dengan tiga ulangan. Faktor pertama adalah bentuk formulasi kulit buah jengkol (B) yaitu cair (B1), bubuk (B2), atau butiran. Faktor ke dua adalah waktu pemberian (W) yaitu saat tanam (W0), 1 (W1), atau 2 minggu setelah tanam (W3). Hasil penelitian menunjukkan aplikasi kulit buah jengkol dalam bnetuk butiran dapat memperbaiki pertumbuhan akar, serapan hara (N, P, K), laju fotosintesis, dan bobot kering akar. Waktu aplikasi kulit buah jengkol dua minggu setelah tanam dapat meningkatkan serapan $\mathrm{N}$ dan $\mathrm{P}$, laju transpirasi dan fotosintesis, serta bobot kering akar.
\end{abstract}

Kata kunci: kulit buah jengkol, bentuk formulasi dan waktu aplikasi, padi sawah asal bibit, serapan hara, pertumbuhan. 


\section{PENDAHULUAN}

Pithecellobium jiringa (Jack) Prain ex King (jengkol, Indon.) merupakan tanaman tahunan yang banyak tumbuh di Bengkulu. Dari total produksi buah jengkol 50-60\%-nya adalah kulit buah, sehingga dalam satu tahun dihasilkan puluhan ton limbah jengkol (kulit buah) di provinsi Bengkulu. Sekitar 20 ton limbah kulit jengkol dibuang setiap harinya di Bengkulu, sedangkan di Jawa Barat sekitar 100 ton. Limbah kulit jengkol ini dapat dimanfaatkan untuk pupuk organik karena banyak mengandung hara N. Pelepasan hara dari kulit buah jengkol bisa melalui proses mineralisasi maupun penguraian humus dari dekomposisi lignin.

Dekomposisi adalah proses penghancuran secara bertahap yang menyebabkan terurainya struktur organisme mati yang semula komplek menjadi bentuk-bentuk yang sederhana seperti air, karbondioksida dan unsur-unsur mineral. Dekomposisi juga dapat diartikan sebagai pemisahan secara mekanik maupun kimiawi struktur tumbuhan mati mulai dari tahap masih terikat pada bahan organik segar sampai menjadi humus yang struktur selnya tidak berbentuk, karena terjadi pemecahan molekul-molekul organik kompleks menjadi karbondioksida, air dan komponen-komponen mineral (Satchell, 1974).

Kecepatan pelepasan alelokimia dari sumbernya tergantung, antara lain dari ukuran bahan. Pemecahan kulit buah jengkol menjadi komponen-komponen yang lebih kecil ukurannya dapat mempercepat proses pelepasan alelokimia. Hal ini dikarenakan pemecahan kulit buah jengkol menyebabkan: (1) kemudahan dalam pemegangan air (Dix dan Webster, 1985) sehingga senyawa fenolat yang larut air mudah terlepas, dan (2) selselnya terpotong-potong sehingga alelokimia yang ada didalamnya mudah dilepaskan (Sastroutomo, 1992).
Selama proses dekomposisi kulit buah jengkol berjalan disamping terjadi proses mineralisasi yang dapat menghasilkan hara juga terjadi pelepasan senyawa alelokimia. Asam fenolat merupakan senyawa yang paling banyak terlepas dari dekomposisi kulit buah jengkol dan dapat menyebabkan akar tanaman keracunan. Oleh karena itu harus dicari bentuk formulasi dan waktu aplikasi kulit buah jengkol yang tidak meracuni pertumbuhan akar sehingga pertumbuhan tanaman tidak terhambat.

\section{METODE PENELITIAN}

Penelitian ini dilaksanakan di rumah kaca fakultas Pertanian UGM pada bulan Oktober 2011. Rancangan percobaan yang digunakan adalah Rancangan Acak Lengkap (RAL) faktorial $3 \times 3+3$ dengan tiga ulangan. Faktor pertama adalah bentuk formulasi kulit buah jengkol (B) yaitu cair (B1), bubuk (B2), atau butiran. Faktor ke dua adalah waktu pemberian (W) yaitu saat tanam (W0), 1 (W1), atau 2 minggu setelah tanam (W3). Sedangkan untuk kontrol tidak diaplikasi kulit buah jengkol. Penelitian ini menggunakan pot plastik volume 5 liter.

Setiap pot plastik diisi tanah kering angin sebanyak $4 \mathrm{~kg}$ dan dicampur dengan kulit buah jengkol sesuai perlakuan, kemudian ditambahkan air bebas ion (Aqualang) sampai kapasitas lapangan. Sebanyak 2 bibit padi umur 3 minggu di tanam pada setiap pot, dan setelah umur satu minggu ditinggalkan satu tanaman. Untuk menjaga kelembaban media maka setiap hari disiram dengan air bebas ion sampai kondisi berlumpur. Air bebas ion didapat dari Laboratorium Ilmu Tanah Faperta UGM di Kuningan. Setiap satu unit percobaan terdiri dari 9 pot.

Pengamatan dilakukan saat umur tanaman 8 minggu setelah tanam. Variabel yang diamati meliputi: panjang dan luas 
Tabel 1. Pengaruh bentuk formulasi alelokimia dan waktu aplikasi kulit buah jengkol terhadap panjang akar $(\mathrm{m})$, luas permukaan akar $\left(\mathrm{m}^{2}\right)$ dan serapan hara NPK

\begin{tabular}{|c|c|c|c|c|c|}
\hline Perlakuan & $\begin{array}{c}\text { Panjang } \\
\text { akar } \\
\text { (m) }\end{array}$ & $\begin{array}{c}\text { Luas } \\
\text { permukaan } \\
\text { akar }\left(\mathbf{m}^{2}\right)\end{array}$ & $\begin{array}{l}\text { Serapan N } \\
\text { mg rumpun }\end{array}$ & $\begin{array}{l}\text { Serapan } P \\
\text { (mg rumpun }\end{array}$ & $\begin{array}{c}\text { Serapan K } \\
\left(\text { mg rumpun }^{-1}\right)\end{array}$ \\
\hline \multicolumn{6}{|c|}{ Formulasi Alelokimia (B) } \\
\hline Cair (B1) & $18.005^{\mathrm{b}}$ & 0.399 & 0.062 & 0.071 & 0.192 \\
\hline Bubuk (B2) & $23.932^{\mathrm{ab}}$ & 0.456 & 0.077 & 0.088 & 0.164 \\
\hline Butiran (B3) & $29.149^{\mathrm{a}}$ & 0.426 & 0.082 & 0.092 & 0.199 \\
\hline \multicolumn{6}{|l|}{ Waktu Aplikasi (W): } \\
\hline Saat tanam (W0) & $22.140^{\mathrm{ab}}$ & 0.658 & 0.070 & 0.083 & 0.206 \\
\hline $1 \mathrm{mst}(\mathrm{W} 1)$ & $28.337^{\mathrm{a}}$ & 0.665 & 0.070 & 0.078 & 0.167 \\
\hline $2 \mathrm{mst}$ (W2) & $20.608^{\mathrm{b}}$ & 0.620 & 0.081 & 0.090 & 0.184 \\
\hline
\end{tabular}

Keterangan: Angka yang diikuti huruf yang sama pada kolom dan baris yang sama tidak berbeda pada DMRT $5 \%$.

permukaan akar, serapan hara $(\mathrm{N}, \mathrm{P}$, dan $\mathrm{K})$, laju fotosintesis dan transpirasi, serta bobot kering akar dan tajuk. Cara menganalisis setiap variabel adalah sebagai berikut: a. panjang dan luas permukaan akar $\left(\mathrm{m}, \mathrm{m}^{2}\right)$ diukur dengan metode perpotongan garis (line intersection) yang dibaca dengan area meter (Indradewa, 2001), b. serapan hara $\mathrm{N}$, P, dan $\mathrm{K}$ (mg.rumpun ${ }^{-1}$ ) dengan destruksi basah menurut metode yang dikembangkan oleh Jones et al. (1991) dan Anonim (2005); c. serapan hara $=$ kadar hara dalam jaringan $\mathrm{x}$ bobot kering tanaman, d. laju fotosintesis

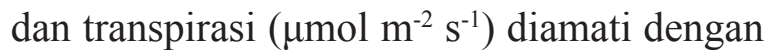
menggunakan Portable Photosynthesis System Licor-6400, e. Bobot kering akar dan tajuk ( g rumpun $^{-1}$ ) diamati dengan metode oven.

Data pengamatan dianalisis dengan sidik ragam menurut rancangan acak kelompok lengkap. Perlakuan yang berpengaruh nyata diuji lanjut dengan menggunakan Duncan multiple range test (DMRT) pada taraf beda nyata $5 \%$.

\section{HASIL DAN PEMBAHASAN}

\section{Panjang dan Luas Permukaan Akar, serta Serapan Hara}

Akar merupakan tempat masuknya mineral atau unsur hara. Panjang akar dan luas akar dipengaruhi oleh faktor eksternal seperti seperti porositas tanah, tersedianya air dan mineral, serta kandungan senyawa alelokimia dalam tanah. Pertumbuhan akar selanjutnya berpengaruh terhadap serapan hara.

Berdasarkan sidik ragam panjang akar perlakuan bentuk formulasi alelokimia dan waktu aplikasi kulit buah jengkol berpengaruh nyata, sedangkan pada variabel luas permukaan akar dan serapan hara menunjukkan hasil berbeda tidak nyata. DMRT 5\% terhadap panjang akar serta nilai rata-rata luas permukaan akar dan serapan hara disajikan pada Tabel 1.

Dari Tabel di atas dapat dijelaskan kulit buah jengkol dalam formulasi butiran nyata merangsang panjang akar bila dibandingkan 
dengan cair. Hal ini disebabkan kulit buah jengkol dalam formulasi butiran lambat melepaskan alelokimia dan ketika terdekomposisi dapat melepaskan hara sehingga dapat dimanfaatkan untuk pertumbuhan tanaman. Nurjannah et al. (2007) melaporkan aplikaksi kulit buah jengkol 10 ton $\mathrm{ha}^{-1}$ pada lahan sawah dapat memperbaiki pertumbuhan padi. Adanya peningkatan panjang akar dikarenakan hasil dekomposisi kulit buah jengkol dapat memperbaiki sifat biologi, fisika dan kimia tanah. Aktivitas mikroorga-nisme dalam mendekomposisi bahan organik menyebabkan terbentuknya ruang pori sehingga struktur tanah menjadi remah. Tanah yang remah mudah ditembus oleh akar sehingga pertumbuhan akar akan lebih baik. Pertumbuhan akar yang lebih baik mengakibatkan serapan hara $\mathrm{N}, \mathrm{P}$, dan $\mathrm{K}$ juga meningkat. Hal ini disebabkan akar dapat memanfaatkan hara yang sudah ada dalam tanah maupun hara hasil dekomposisi kulit buah jengkol. Dekomposisi kulit buah jengkol dapat melepaskan C, N, P, K, Ca dan $\mathrm{Mg}$.

Aplikasi kulit buah jengkol 1 mst nyata memperbaiki pertumbuhan panjang akar bila dibandingan dengan 2 mst. Hal ini disebabkan aplikasi kulit buah jengkol 2 mst menyebabkan ketidaksesuaian antara kebutuhan dan ketersediaan hara. Atmojo (2003) menyatakan pupuk hijau yang berasal dari legum dapat diberikan seawal mungkin tanpa mengalami proses pengomposan karena kadar $\mathrm{N}$ dalam tanaman relatif tinggi.

Berdasarkan sidik ragam luas permukaan akar perlakuan bentuk formulasi alelokimia dan waktu aplikasi kulit buah jengkol maupun interaksinya tidak berpengaruh nyata. Hal ini disebabkan padi yang ditanam adalah bibit umur 21 hst sehingga sudah relatif tahan terhadap alelokimia kulit buah jengkol. Moenandir (1988), Macias et al. (1996) dan Gonzales et al. (1997) menyatakan kepekaan tanaman terhadap toksisitas alelokimia menurun dengan semakin tuanya umur tanaman.

Serapan hara merupakan hasil kali antara kadar hara pada tanaman dengan bobot kering tanaman. Semakin baik pertumbuhan tanaman maka serapan serapan hara juga semakin tinggi. Serapan hara dipengaruhi antara lain oleh laju transpirasi, pertumbuhan, kadar hara dalam tanah, dan alelokimia yang berada disekitar perakaran.

Berdasarkan sidik ragam memperlihatkan perlakuan bentuk formulasi alelokimia dan waktu aplikasi kulit buah jengkol serta interaksinya tidak berpengaruh nyata pada serapan N, P dan K. Hal ini membuktikan bahwa alelokimia kulit buah jengkol secara nyata tidak meracuni pertumbuhan akar padi pindah tanam sehingga serapan hara juga tidak terpengaruh. Namun demikian aplikasi kulit buah jengkol dalam bentuk butiran dapat memperbaiki serapan N, P dan K. Hal ini disebabkan dekomposisi kulit buah jengkol dapat melepaskan hara, dan $\mathrm{N}$ merupakan hara yang paling banyak dilepaskan pada awal proses dekomposisi. Gusnidar et al. (2011) menyatakan aplikaksi kulit buah jengkol 20 ton ha $^{-1}$ pada tanah sawah dapat meningkatkan ketersediaan $\mathrm{N}, \mathrm{P}$ dan $\mathrm{K}$.

\section{Laju Fotosintesis dan Transpirasi, Berat Kering Akar dan Tajuk}

Fotosintesis adalah proses penangkapan energi cahaya yang diubah menjadi energi kimia dan hasilnya disimpan dalam bentuk karbohidrat. Hasil fotosintesis tergantung pada nilai selisih antara nilai fotosintesis dan respirasi dimana batasan tanaman dianggap tidak terjadi pertumbuhan jika nilai tersebut sebanding. Laju fotosintesis dipengaruhi oleh kondisi tanaman. Pada tanaman yang stres karena keracunan alelokimia akan mengalami penurunan fotosintesis. Bernat et al. (2007) membuktikan ekstrak bunga matahari dengan 
Tabel 2. Pengaruh bentuk formulasi alelokimia dan waktu aplikasi kulit buah jengkol terhadap laju fotosintesis, laju transpirasi, berat kering akar dan tajuk

\begin{tabular}{|c|c|c|c|c|}
\hline Perlakuan & 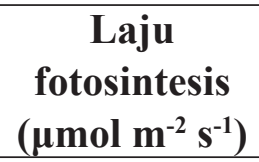 & 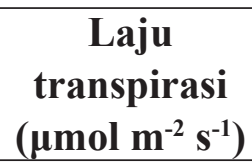 & $\begin{array}{c}\text { Berat kering } \\
\text { akar } \\
\text { (g rumpun }^{-1} \text { ) }\end{array}$ & $\begin{array}{c}\text { Berat kering } \\
\text { tajuk } \\
\text { (g rumpun }^{-1} \text { ) }\end{array}$ \\
\hline \multicolumn{5}{|l|}{ Interaksi $\left(\mathrm{B}^{*} \mathrm{~W}\right)$ : } \\
\hline B1W0 & 23.225 & 8.657 & 1.047 & 7.510 \\
\hline B1W1 & 24.217 & 9.037 & 1.093 & 6.517 \\
\hline B1W2 & 27.392 & 10.710 & 1.230 & 6.307 \\
\hline $\mathrm{B} 2 \mathrm{~W} 0$ & 22.742 & 10.400 & 1.143 & 6.883 \\
\hline B2W1 & 25.633 & 8.767 & 1.087 & 6.523 \\
\hline B2W2 & 24.883 & 9.687 & 1.183 & 7.077 \\
\hline B3W0 & 23.825 & 9.217 & 1.067 & 6.683 \\
\hline B3W1 & 26.533 & 11.030 & 1.180 & 7.230 \\
\hline B3W2 & 24.792 & 9.523 & 1.093 & 6.463 \\
\hline
\end{tabular}

Keterangan: Angka yang diikuti huruf yang sama pada kolom dan baris yang sama tidak berbeda pada DMRT $5 \%$.

kadar 5\% (w. $\left.\mathrm{v}^{-1}\right)$ menyebabkan penurunan laju fotosintesis sebesar $74 \%$ pada mustard.

Berdasarkan sidik ragam laju fotosintesis dan transpirasi, serta bobot kering akar dan tajuk perlakuan bentuk formulasi alelokimia dan waktu aplikasi kulit buah jengkol serta interaksinya tidak berpengaruh nyata pada laju fotosintesis. Hasil rata-rata terhadap laju fotosintesis dan transpirasi, serta bobot kering akar dan tajuk disajikan pada Tabel 2.

Tabel 2 di atas membuk-tikan bahwa kulit buah jengkol tidak bersifat racun pada padi pindah tanam asal bibit umur 21 hst. Semakin tua umur tanaman maka ketahanan terhadap gangguan lingkungan juga semakin tinggi. Pada tanaman yang lebih tua maka pembentukan dinding sel juga lebih tebal dan kuat sehingga lebih tahan terhadap alelokimia Setyowati et al. (2010) menyatakan ekstrak air bandotan tidak menghambat pertum- buhan tanaman sawi pindah tanam asal bibit berdaun 4, justru merangsang. Pada tanaman padi umur 21 hari maka pertumbuhan akar sekunder sudah terjadi sehingga jika terjadi kerusakan pada akar primer maka akan digantikan oleh akar sekunder. Hal ini juga menjadi salah satu penyebab mengapa padi pindah tanam lebih tahan terhadap gangguan alelokimia.

\section{KESIMPULAN}

Aplikasi kulit buah jengkol tidak menghambat pertumbuhan akar maupun tajuk padi pindah tanam umur 21 hari. Kulit bauh jengkol yang diaplikasikan dalam bentuk butiran dapat memperbaiki partumbuhan akar melalui variabel panjang akar sehingga berpengaruh juga terhadap peningkatan serapan hara, laju fotosintesis dan transpirasi, serta bobot kering akar. 


\section{DAFTAR PUSTAKA}

Anonim. 2005. Analisis kimia tanah, tanaman, air, dan pupuk. Balai Penelitian Tanah, Badan Penelitian dan Pengembangan Pertanian, Departemen Pertanian, Bogor.

Atmojo, S.W. 2003. Peranan bahan organik terhadap kesuburan tanah dan upaya pengelolaannya. Pidato pengukuhan guru besar. Universitas Sebelas Maret. Surakarta.

Bernat, W., H. Gawronska, and S.W. Gawronski. 2007. Physiological Effects of allelopathic activity of sunflower on mustard. Allelopathy J. 19(1): 1-10.

Delvin, M.D. and F.H. Witham. 1983. Plant physiology. Boston : Willard Grant Press.

Gardner, F.P., R.B. Pearce, and R.L. Mitchel. 1991. Physiology of crop plant metabolisme. San Francisco: Freeman . Cooper \& Company. 592 pp.

Gonzalez, L., X.C. Souto, and M.J. Reigosa. 1997. Weed control by Capsicum annuum. Allelopathy J. No. 4: 101-109

Gusnidar, Yulnafatmawati, Nofianti. 2011. Pengaruh kompos asal kulit buah jengkol (Pithecellobium jiringa (Jack) Prain ex King terhadap ciri kimia tanah sawah dan produksi tanaman padi. J. Solum. 8(2) : 17-27.

Harbone, J.B. 1987. Phytochemical Methodes. (Metode Fitokimia. Penuntun cara modern menganalisis tumbuhan). Diterjemahkan oleh Padmawinata K., dan I. Soediro. ITB, Bandung.

Indradewa, D. 2001. Gatra agronomis dan fisiologis pengaruh genangan dalam parit pada tanaman kedelai. Disertasi. Universitas Gajah Mada, Yogyakarta. 302 hal.
Jones, J.B., B. Wolf, and H.A. Mills. 1991. Plant analysis handbook. Micro-Macro Pub. Georgia. 213 pp.

Macias, F.A., J.M.G. Molinillo, J.C.G. Galindo, RM.Varela, RM. Simonetx, and D. Castellano. 2001. The use of allelopathic studies in the search for natural herbicides. In: Allelopathy in Agroecosystems. Kohli R.K., H.P. Singh, and D.R. Batish. Food Products Press an Imprint of the Howarth Press, Inc. New York-London-Oxford. pp 237-256.

Nurjannah, U., B.W. Simanihuruk, Hasanudin, dan B.N. Achmadi. 2007. Bioherbisida kulit buah jengkol untuk menekan pertumbuhan gulma padi sawah. Akta Agrosia, No. 2:147-154.

Sastroutomo, S.S. 1992. Ekologi gulma. Gramedia Pustaka Utama, Jakarta.

Satchell, J.E. 1974. Litter-interference of animate/inanimate matter. In: Biology of plant litter decomposition. Vol. 1 . C.H. Dickinson dan G.J.F. Pugh (eds.). Academic Press. London, New York.

Setyowati, N., U. Nurjanah, dan D.A. Togatorop. 2010. Allelopathic effect of Wedelia trilobata, Ageratum conyzoides, Chromolaena odorata and Mikania micrantha on green mustard growth. Proc. Int. Conf. on Bioscience and Biotechnology. Ramona, Y., M. Pharbawati, Y. Ciawi (eds.). Bali 23 24 Sept. 2010.

Sitompul, S.M. dan B. Guritno. 1995. Analisis pertumbuhan Tanaman. Yogyakarta: Gajah Mada University Press. 412 hal.

Taiz, L., and E. Zeiger. 2002. Plant physiology. Third Edition. Massachussets: Sinauer Associates. Inc. Publishers. 
Togatorop, D.N., N. Setyowati, dan U. Nurjanah. 2010. Studi alelopati Wedelia trilobata, Ageratum conyzoides, Chromolaena odorata dan Mikania micrantha terhadap pertumbuhan dan hasil sawi. Pros. Sem. Nas. Dan Rapat Tahunan Dekan Bidang Ilmu-ilmu Pertanian. Marwanto, Hermansyah, N. Setyowati (eds.). Bengkulu, 23 -25 Mei 2010.
Veen, R.V.D. ang G. Meijer. 1962. Light and plant grotwh. The Macmillan Company. 75-86pp.

Yoshida, S. 1981. Fundamental of rice crop science. Los Banos, Philippines: International Rice Research Institute. 